\title{
Impact of the underlying etiology of growth hormone deficiency on serum IGF-I SDS levels during GH treatment in children
}

\author{
Juliane Léger1,2,3, Damir Mohamed 4,5, Sophie Dos Santos', Myriam Ben Azoun1, Delphine Zénaty1, \\ Dominique Simon', Anne Paulsen ${ }^{1}$, Laetitia Martinerie ${ }^{1,2,3}$, Didier Chevenne ${ }^{6}$, Corinne Alberti ${ }^{2,4,5}$, \\ Jean-Claude Carel ${ }^{1,2,3}$ and Sophie Guilmin-Crepon ${ }^{1,4,5}$
}

\begin{abstract}
${ }^{1}$ Assistance Publique-Hôpitaux de Paris, Hôpital Universitaire Robert Debré, Service d'Endocrinologie Diabétologie Pédiatrique, Centre de Référence des Maladies Endocriniennes Rares de la Croissance et du développement, Paris, France, ${ }^{2}$ Université Paris Diderot, Sorbonne Paris Cité, Paris, France, ${ }^{3}$ Institut National de la Santé et de la Recherche Médicale (Inserm), Unité 1141, DHU Protect, Paris, France, ${ }^{4}$ Assistance Publique-Hôpitaux de Paris, Hôpital Universitaire Robert Debré, Unit of Clinical Epidemiology, Paris, France, ${ }^{5}$ Inserm, CIC-EC 1426, Paris, France, and ${ }^{6}$ Assistance Publique-Hôpitaux de Paris, Hôpital Universitaire Robert Debré, Service de Biochimie-Hormonologie, Paris, France
\end{abstract}

\author{
Correspondence \\ should be addressed \\ to $J$ Léger \\ Email \\ juliane.leger@aphp.fr
}

\begin{abstract}
Context: Regular monitoring of serum IGF-I levels during growth hormone (GH) therapy has been recommended, for assessing treatment compliance and safety.

Objective: To investigate serum IGF-I SDS levels during GH treatment in children with GH deficiency, and to identify potential determinants of these levels.

Design, patients and methods: This observational cohort study included all patients $(n=308)$ with childhood-onset non-acquired or acquired GH deficiency (GHD) included in the database of a single academic pediatric care center over a period of 10 years for whom at least one serum IGF-I SDS determination during GH treatment was available. These determinations had to have been carried out centrally, with the same immunoradiometric assay. Serum IGF-I SDS levels were determined as a function of sex, age and pubertal stage, according to our published normative data.

Results: Over a median of $4.0(2-5.8)$ years of GH treatment per patient, 995 serum IGF-I SDS determinations were recorded. In addition to BMI SDS, height SDS and GH dose $(P<0.01)$, etiological group $(P<0.01)$ had a significant effect on serum IGF-I SDS levels, with patients suffering from acquired GHD having higher serum IGF-I SDS levels than those with non-acquired GHD, whereas sex, age, pubertal stage, treatment duration, hormonal status (isolated GHD (IGHD) vs multiple pituitary hormone deficiency (MPHD)) and initial severity of GHD, had no effect.

Conclusions: These original findings have important clinical implications for long-term management and highlight the need for careful and appropriate monitoring of serum IGF-I SDS and GH dose, particularly in patients with acquired GHD, to prevent the unnecessary impact of potential comorbid conditions.
\end{abstract}

\section{Introduction}

The regular monitoring of serum IGF-I levels during growth hormone (GH) therapy, to ensure that these levels remain within the normal range for age and sex, has been recommended, to assess treatment compliance and safety, in terms of the potential long-term risk of cancer $(1,2$,
() 2017 European Society of Endocrinology Printed in Great Britain
3 , 4). However, there are limitations to the use of this approach and care is required in the standardization of results as a function of age and sex, because various factors may affect interpretation of the measurement. Indeed, serum IGF-I concentrations are influenced not only by

Published by Bioscientifica Ltd. 
age and sex, but also by pubertal status and nutritional factors, and by chronic conditions, such as those associated with nutritional and inflammatory problems (5). Normative values are also assay-dependent $(6,7)$. We previously developed a model formula for calculating s.D. scores as a function of age (for children aged six years or over), sex and pubertal stage for a particular assay used in our institution. We also demonstrated the impact of BMI SDS and height SDS on the interpretation of these measurements (8).

The determination of IGF-I and its standardization present their own difficulties, and studies on IGF-I SDS during the treatment of children with GH deficiency are therefore scarce $(9,10,11,12,13,14,15,16)$. Most studies to date have concerned small series of patients and many did not involve the systematic evaluation of serum IGF-I levels with the same assay, or evaluated the relationship between GH dose, serum IGF-I SDS and growth responses mostly during the first two years of $\mathrm{GH}$ treatment, resulting in a lack of relationship $(9,10,12,13,15)$ or only an apparently poor $(14,17)$ relationship being identified between these two factors, probably due to the high degree of individual variability in IGF-I concentration and growth responsiveness and the narrow range of $\mathrm{GH}$ doses used in children with GH deficiency. At higher doses of GH, corresponding to about twice the usual dose, the dose-dependent change in IGF-I SDS concentration has been shown to be related to the prepubertal (11) and pubertal (17) gain in height SDS. However, none of the studies performed to date investigated the effect of GHD etiology as a factor potentially explaining the variability of serum IGF-I SDS. We hypothesized that variables related to $\mathrm{GH}$ deficiency, including the heterogeneous nature of the disease, would probably make a significant contribution to the determinism of serum IGF-I SDS during $\mathrm{GH}$ treatment.

We therefore investigated the serum IGF-I SDS recorded during monitoring while on GH treatment, in a large cohort of children with GH deficiency, and tried to identify factors that might account for serum IGF-I SDS.

\section{Subjects and methods}

\section{Patients}

This observational cohort study included all patients with childhood-onset GHD identified in the database of the Pediatric Endocrinology Department of Robert Debré Hospital in Paris who had been followed up in our department between 2004 and 2013. The inclusion criteria for the study were treatment with GH during this period (this period was chosen because serum IGF-I levels were determined with the same assay throughout), and at least one serum IGF-I determination performed at our central laboratory during GH treatment, in patients with a chronological age of at least six years (because our normative data for IGF-I SDS determinations begin at the age of six years). The exclusion criteria were patients for whom serum IGF-I concentration had not been determined in our laboratory $(n=31)$, with other known chronic diseases $(n=26)$, with no brain MRI performed during the initial investigation or follow-up $(n=3)$, or with a lack of compliance with GH treatment in the opinion of the pediatrician at the outpatient clinic or declared by the parents and/or the child $(n=4)$. In total, 308 patients with childhood-onset GHD meeting the inclusion criteria were included in the study (Fig. 1, flow chart).

The characteristics of the participants $(n=308)$ and non-participants $(n=64)$ at the time of GHD diagnosis are shown in the table in the Supplementary data (see section on supplementary data given at the end of this article). The study population was slightly younger at diagnosis, but otherwise representative of the entire population treated for GHD during childhood, as shown by the sex distribution, the severity of GHD as assessed on the basis of height, height deficit with respect to target height at diagnosis (target height SDS minus height SDS), GH peak at diagnosis, whether GHD was isolated or associated with MPHD and the etiology of GHD (non-acquired vs acquired GHD).

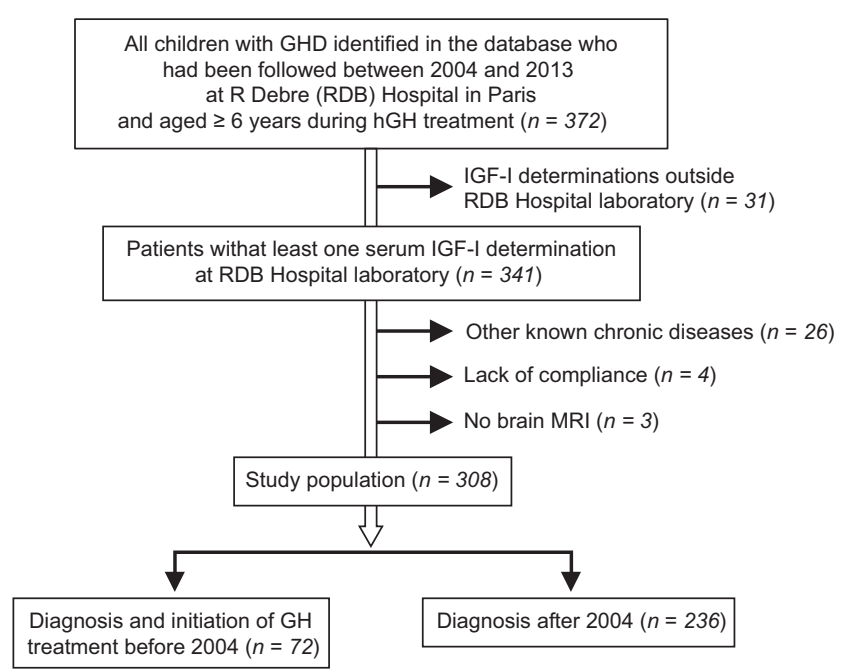

Figure 1

Flow chart of the study. 


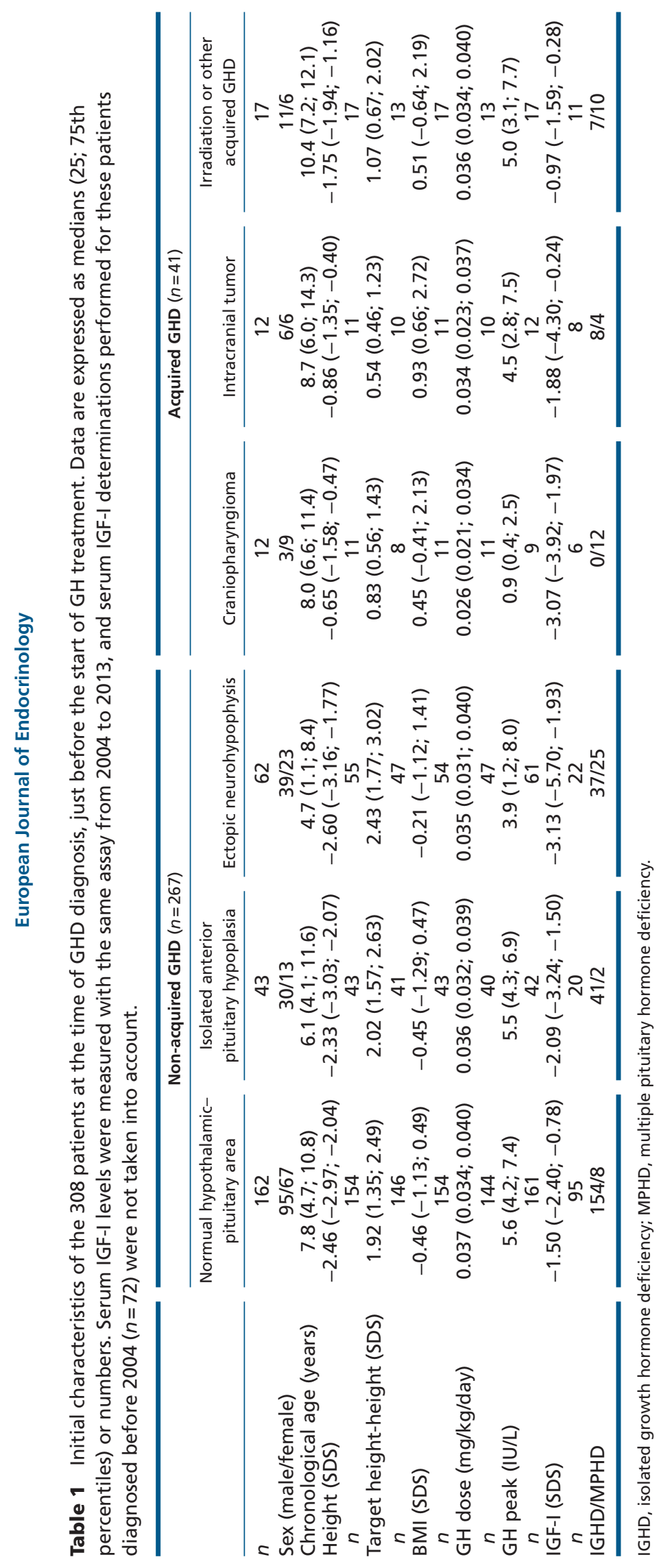

The study population consisted of two subgroups: 267 (87\%) patients with non-acquired GHD and 41 (13\%) patients with acquired GHD. The clinical characteristics of the patients at the time of GHD diagnosis, before GH treatment and at the last evaluation on treatment, as a function of MRI findings in cases of non-acquired GHD and of the cause of acquired GHD, are indicated (Tables 1 and 2). For patients with non-acquired GHD, those with ectopic neurohypophysis $(n=62)$ were younger, had a significantly greater height deficit with respect to target height, and a lower serum IGF-I SDS and GH peak in pharmacological tests at diagnosis. They also had a higher frequency of MPHD (as opposed to IGHD) than those with isolated anterior pituitary hypoplasia $(n=44)$ or with normal MRI findings $(n=161)$. For those with acquired GHD, patients with craniopharyngioma $(n=12)$ had a more severe pituitary deficiency, as attested by serum IGF-I SDS and GH peak levels and the presence of MPHD, than those with a history of other tumors of the hypothalamo-pituitary area $(n=12)$ (optic nerve glioma, astrocytoma, Rathke's cleft cysts and rhabdomyosarcoma of the sphenoidal sinus) or those with a history of brain radiotherapy $(n=13)$ or infiltrative disease with diabetes insipidus $(n=4)$.

The patients received additional replacement therapy, including L-thyroxine, hydrocortisone, sex steroid therapy and/or desamino-D-arginine-vasopressin (DDAVP), if deficiencies in thyroid-stimulating hormone (TSH, $n=56$ ), adrenocorticotropic hormone (ACTH, $n=34$ ), or gonadotropin (Follicle-Stimulating Hormone (FSH) and LH, $n=34 ; n=20$ boys, $n=14$ girls), and/or central diabetes insipidus $(n=20)$, were diagnosed (MPHD, $n=76$ patients diagnosed either at the initial evaluation $(n=61)$ or during follow-up $(n=15))$.

As expected, height SDS increased, resulting in a significant decrease in height deficit with respect to target height SDS, from a baseline of $2.1(1.4 ; 2.6)$ and $0.9(0.5 ; 1.5)$ SDS to $0.6(-0.2 ; 1.4)$ and $0.3(-0.6 ; 1.3)$ SDS at the last evaluation, for patients with non-acquired and acquired GHD respectively.

\section{Study protocol}

Clinical data for the patients were obtained from their medical records, on standardized data collection forms completed retrospectively at the time of GHD diagnosis and at each evaluation, with the results of serum IGF-I SDS determination. The following were recorded at GHD diagnosis, before the initiation of treatment: sex; height of the parents, etiology of GHD, brain MRI findings. Age, height, weight, pubertal status and the presence of 
associated anterior pituitary deficiencies (MPHD) were assessed and recorded at diagnosis and during follow-up.

Patients received a daily subcutaneous injection of open-label hGH at a median (25-75th percentiles) initial dose of $36(33-40) \mu \mathrm{g} / \mathrm{kg} /$ day, corresponding to the standard dose used in France during the study period. The dose was adjusted according to a balance between weight on a GH dose between 20 and $35 \mu \mathrm{g} / \mathrm{kg} / \mathrm{day}$, height outcome and target IGF-I SDS levels between -2 and +2 SDS. For safety reasons, if IGF-I levels reach an SDS of more than 2.5 for chronological age, sex and pubertal stage relative to reference values, at two consecutive measurements, guidelines recommend decreasing the dose by $10 \%$.

Patients underwent a physical examination at baseline and at subsequent visits, which took place at intervals of about six months. Height, weight and pubertal status were assessed. Serum IGF-I concentration was determined at sixto 12-month intervals, at the discretion of the investigator, but not all determinations were performed at our central laboratory. Given the considerable heterogeneity in testing methods, we retained only centrally determined serum IGF-I SDS values for the analysis.

The study protocol was approved by the Paris Nord Ethics Review Committee for Biomedical Research Projects (CEERB) (No. 12-029).

\section{Methods}

Childhood-onset GHD was diagnosed on the basis of a GH peak of less than 20IU/L in two pharmacological tests, one of which was the insulin tolerance test (insulin, $0.1 \mathrm{IU}$ per kilogram body weight given intravenously as a bolus) in most patients (Table 2). The highest value for the two tests was considered for the analysis. Sex steroid priming was used before GH stimulation tests in prepubertal boys over the age of 11 years and prepubertal girls over the age of 10 years, to improve diagnostic specificity and to prevent inappropriate GH treatment in children with constitutional delays of growth and puberty.

As previously described (18), a complete evaluation of other anterior pituitary functions was carried out in all patients at diagnosis and was repeated during follow-up if deemed necessary, based on clinical examination and serum free T4 and morning cortisol determinations. TSH deficiency was diagnosed as a plasma T4 concentration below $10 \mathrm{pmol} / \mathrm{L}$ and/or abnormal TSH stimulation after Thyrotropin-Releasing Hormone (TRH) administration (normal values for TSH were $0.5-6,14 \pm 7$, and $<8 \mathrm{U} / \mathrm{L}$ for basal, peak, and 120 min post-TRH administration levels

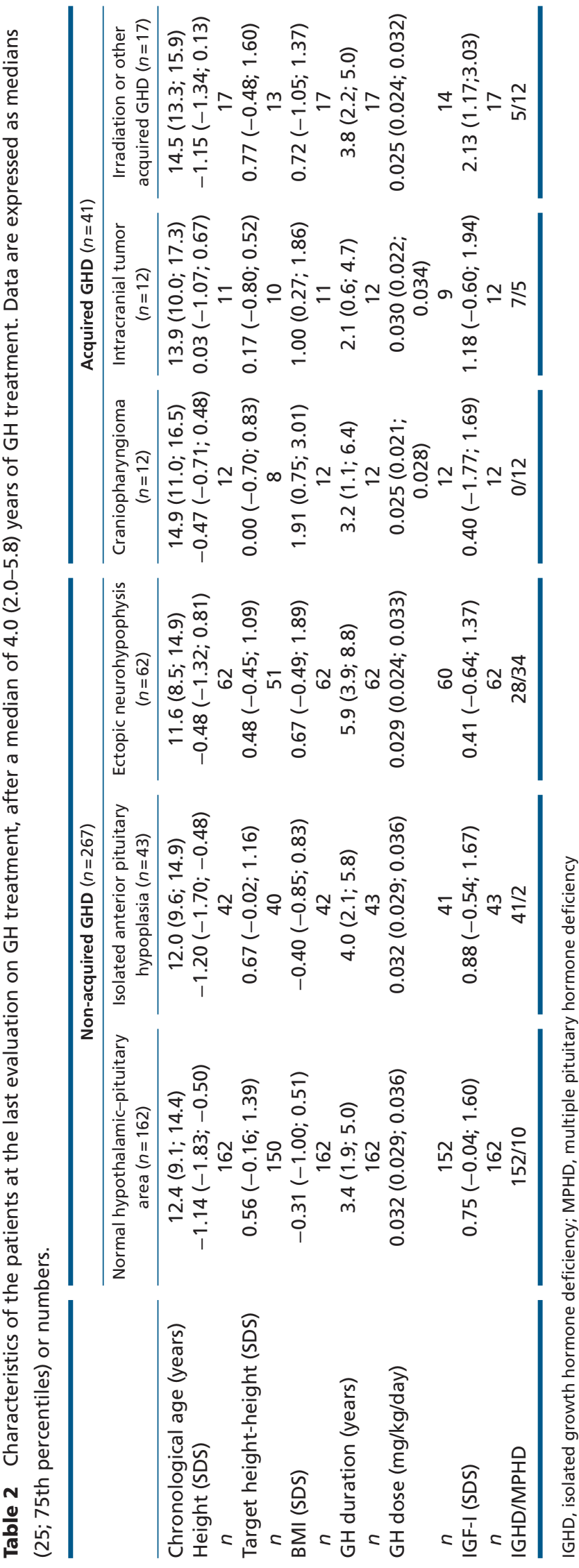


respectively). ACTH deficiency was diagnosed as a morning basal plasma cortisol concentration below $165 \mathrm{nmol} / \mathrm{L}$ and a plasma cortisol concentration below $415 \mathrm{nmol} / \mathrm{L}$ during insulin-induced hypoglycemia. We did not systematically evaluate corticotropin reserves if morning cortisol concentration exceeded $275 \mathrm{nmol} / \mathrm{L}$. Evaluations of the pituitary-gonadal axis were mostly clinical. Patients were considered to have no deficiency if spontaneous pubertal development occurred. Gonadotropin deficiency was suspected in patients showing no pubertal development at a normal pubertal age, as assessed by the determination of plasma sex steroid levels and FSH and LH levels after Gonadotropin-Releasing Hormone tests or after the induction of puberty. Central Diabetes Insipidus was defined on the basis of abnormal thirst (polydipsia/adipsia) with hypernatremia $(\geq 146 \mathrm{mmol} / \mathrm{L})$ associated with an inappropriately low urine osmolality $(<300 \mathrm{mosmol} / \mathrm{kg})$. MPHD was defined as GHD associated with abnormal levels of at least one of the other anterior pituitary hormones.

MRI was initially carried out either at the time of GHD diagnosis or shortly after the initiation of hGH treatment. The anterior pituitary was considered to be hypoplastic if its height was below -2 SDS for age (19). We also checked for the presence of an ectopic posterior pituitary hyperintense signal on MRI.

Height and BMI (weight/(height) ${ }^{2}$ in $\mathrm{kg} / \mathrm{m}^{2}$ ) are expressed as SDS $(20,21)$. Pubertal development was assessed by determining Tanner stage. Target height SDS was calculated from mid-parental height (22).

Serum IGF-I concentrations were measured by immunoradiometry (IGF-I RIACT, Cisbio Bioassays, Gif sur Yvette, France). The interassay coefficient of variation was $<9 \%$ and the limit of detection was $9 \mathrm{ng} / \mathrm{mL}$. Serum concentrations are expressed as s.D. scores for age, sex and pubertal stage, according to our normative data (8).

\section{Statistical analysis}

Data are expressed as medians (25th-75th percentiles) for continuous variables or numbers (percentage) for categorical variables. For comparisons of the characteristics of different groups of patients, we used the twotailed Wilcoxon test for quantitative variables and the Chi-squared test for categorical variables. There was no adjudication for missing data. A linear mixed model for repeated measures was used to investigate the association between serum IGF-I SDS levels and other parameters, such as sex, age, pubertal status, height SDS, BMI SDS, GH dose, duration of GH treatment per six-month period, etiological group (two categories: non-acquired vs acquired GHD), hormonal status (IGHD vs MPHD), the severity of GH deficiency based on the highest GH peak for the two pharmacological tests. For the multivariate linear mixed model, we entered all independent variables correlated with serum IGF1-SDS at the $P<0.20$ level in univariate analysis. We then examined the effects of potential mediators by adjusting this model for sex and GH dose, and investigated the collinearity of all variables in the multivariate analysis. Finally, interactions between etiological group and BMI SDS, between etiological group and height SDS and between BMI SDS and hormonal status (IGHD vs MPHD) were also investigated.

Statistical significance was defined as $P<0.05$. The analyses were conducted with SAS software (version 9.4, SAS Institute Inc., Cary, North Carolina, USA).

\section{Results}

In total, 995 centrally determined serum IGF-I SDS values obtained during GH treatment were analyzed, with a median of $3.0(2.0 ; 4.5)$ measurements per patient during a median follow-up of $4.0(2.0 ; 5.8)$ years.

Median serum IGF-I SDS levels increased significantly during the first six months of treatment $(P<0.0001)$, remaining stable thereafter, with no median difference between years, for the entire group (Fig. 2). Individual serum IGF-I SDS values are shown as a function of treatment duration and age in Fig. 3A and B respectively. Individual patient data did not depend on patient age or treatment duration, and serum IGF-I SDS values were in the normal range for most patients, with wide individual

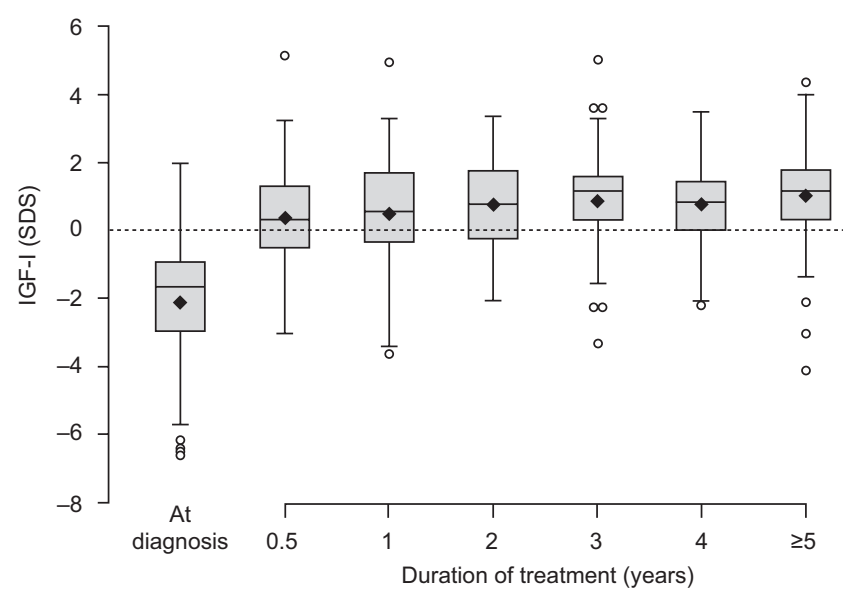

\section{Figure 2}

Median serum IGF-I SDS during GH treatment in children with growth hormone deficiency. Median, interquartile range and range are shown. 

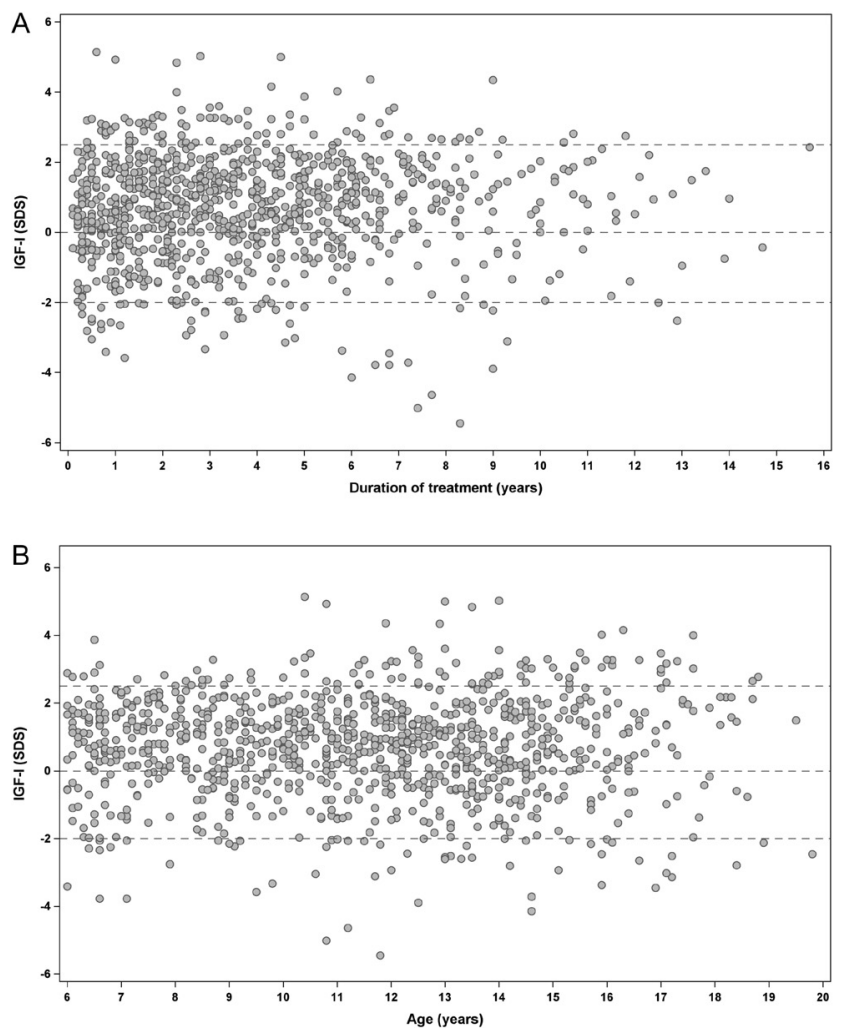

Figure 3

Individual serum IGF-I SDS during GH treatment, in children with growth hormone deficiency. (A) As a function of treatment duration. (B) As a function of age. variation. However, very low and high serum IGF-I SDS values were observed, ranging from -5.4 to +5.1 SDS, with 95 serum IGF1 values $>2.5$ SDS obtained from 56 patients with a high serum IGF-1 SDS on at least one occasion during GH treatment and with 54 individual serum IGF1 determinations $<-2$ SDS obtained from 35 patients, during follow-up.

\section{Factors associated with serum IGF-I SDS during GH treatment}

Univariate linear mixed model analysis revealed significant independent associations between individual serum IGF-I SDS during GH treatment and height SDS, BMI SDS and etiological group $(P<0.01)$. No collinearity between variables was observed in the multivariate model. The multivariate model revealed that, throughout the study period and in addition to the effect of BMI SDS and height SDS $(P<0.01)$, etiological group remained significantly associated with serum IGF-I SDS levels $(P<0.01)$, with patients suffering from acquired GHD having a higher serum IGF-I SDS during treatment than those with nonacquired GHD. Moreover, a positive association between GH dose and serum IGF-I SDS level $(P<0.01)$ was identified in the adjusted multivariate model (Table 3). Similar results were obtained for analyses of the raw data for serum IGF-I concentration (serum IGF-I concentration in $\mathrm{ng} / \mathrm{mL}$ after logarithmic transformation due to the non-Gaussian

Table 3 Bi- and multivariate linear mixed models analyzing serum IGF-I SDS levels during GH treatment in children with GHD.

\begin{tabular}{|c|c|c|c|c|}
\hline & \multicolumn{2}{|c|}{ Model 1 (bivariate analysis) } & \multicolumn{2}{|c|}{ Model 2 (multivariate analysis) $n=965$} \\
\hline & B $(95 \% \mathrm{Cl})$ & $P$-Value & B $(95 \% \mathrm{Cl})$ & $P$-Value \\
\hline \multicolumn{5}{|l|}{ Sex } \\
\hline Male & - & 0.80 & - & 0.68 \\
\hline Female & $-0.04(-0.32 ; 0.25)$ & & $-0.05(-0.32 ; 0.23)$ & \\
\hline Age (years) & $-0.01(-0.05 ; 0.03)$ & 0.58 & - & - \\
\hline \multicolumn{5}{|l|}{ Tanner stage } \\
\hline 1 & - & 0.58 & - & - \\
\hline $2-3$ & $-0.08(-0.29 ; 0.13)$ & & & \\
\hline 4-5 & $-0.14(-0.43 ; 0.15)$ & & & \\
\hline Height (SDS) & $0.20(0.10 ; 0.29)$ & $<0.01$ & $0.16(0.05 ; 0.27)$ & $<0.01$ \\
\hline BMI (SDS) & $0.23(0.15 ; 0.31)$ & $<0.01$ & $0.29(0.20 ; 0.38)$ & $<0.01$ \\
\hline GH duration (months) & $0.00(-0.00 ; 0.01)$ & 0.18 & $-0.00(-0.01 ; 0.00)$ & 0.50 \\
\hline GH dose $(\mu \mathrm{g} / \mathrm{kg} / \mathrm{day})$ & $0.004(-0.010 ; 0.018)$ & 0.59 & $0.03(0.01 ; 0.04)$ & $<0.01$ \\
\hline GH peak at diagnosis (IU/L) & $-0.02(-0.07 ; 0.02)$ & 0.26 & - & - \\
\hline \multicolumn{5}{|l|}{ Hormonal status } \\
\hline IGHD & - & 0.26 & & 0.19 \\
\hline MPHD & $0.18(-0.13 ; 0.50)$ & & $-0.25(-0.61 ; 0.12)$ & \\
\hline \multicolumn{5}{|l|}{ GHD etiology } \\
\hline Non-acquired & - & $<0.01$ & & $<0.01$ \\
\hline Acquired & $0.61(0.21 ; 1.01)$ & & $0.75(0.30 ; 1.20)$ & \\
\hline
\end{tabular}




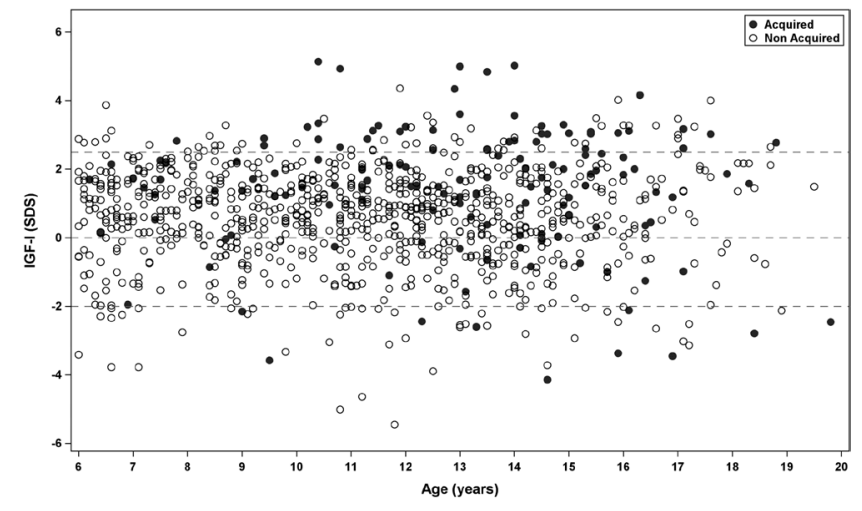

\section{Figure 4}

Individual serum IGF-I SDS as a function of age during GH treatment, in children with growth hormone deficiency, by etiological group (acquired vs non-acquired GHD).

distribution of the data) (Supplementary data). The only interaction identified was between etiological group and BMI SDS $(P<0.01)$, suggesting a higher impact of BMI SDS on serum IGF-I SDS in patients with non-acquired GHD than in those with acquired GHD. We plotted individual serum IGF-I SDS values on GH treatment for patients from the two etiological groups (non-acquired vs acquired GHD) as a function of age throughout the study period (Fig. 4). Patients with acquired GHD had significantly higher IGF-I SDS levels than those with non-acquired GHD. As expected, the proportion of patients with at least one serum IGF-I level above 2.5 SDS during GH treatment was higher for the acquired GHD group than for the nonacquired GHD group ( $n=17 / 41,41 \%$ vs $n=39 / 267,15 \%)$. However, the proportions of patients with at least one serum IGF-I level below -2 SDS were similar in the two etiological groups ( $n=5 / 41,12 \%$ vs $n=30 / 267,11 \%$ ).

No difference in serum IGF-I SDS values was found between the three subgroups of patients with acquired GHD or the three subgroups of patients with non-acquired GHD (data not shown). Sex, age, pubertal stage, duration of $\mathrm{GH}$ treatment, hormonal status (IGHF vs MPHD) and initial severity of GHD, as assessed by GH peak in pharmacological tests at diagnosis, had no significant effect on serum IGF-I SDS levels (Table 3).

\section{Discussion}

This large observational cohort study provided extensive data for the assessment of serum IGF-I SDS, with a standardized assay, during long-term GH treatment, in a well-characterized cohort of children with GH deficiency treated at a single center. One of the key findings of this study was the first ever demonstration of an interesting association between serum IGF-I SDS during GH treatment and GH etiology, with serum IGF-I SDS significantly higher in patients with acquired GHD than in those with non-acquired GHD. In addition, serum IGF-I SDS during treatment was also found to be positively correlated with BMI SDS, height SDS and GH dose.

Consistent with our previous findings based on brain MRI imaging for the categorization of GHD severity at the time of diagnosis, before GH treatment (18), median serum IGF-I SDS at diagnosis was related to disease severity in the various etiological groups of patients with non-acquired GHD. With the exception of patients with craniopharyngioma, values were higher for patients with acquired GHD than for those with nonacquired GHD. The patients with acquired GHD were also taller and had a higher BMI SDS at diagnosis than those with non-acquired GHD. Serum IGF-I SDS increased after treatment initiation in all groups, but, consistent with other reports $(10,14,23)$, was found to be independent of treatment duration, with median values remaining stable from six months after the start of treatment until the final evaluation, although most reports, with the exception of three studies concerning patients with a treatment duration of three to five years $(15,16,17)$, described findings for the first one to two years of treatment only $(9,10,11,12,13,14)$.

Unlike previous studies in children $(11,14)$ and adults (24) showing an association between serum IGF-I SDS and sex and a weak association between serum IGF-I SDS and age (14), we also clearly demonstrated that sex, age, duration of treatment, pubertal stage, hormonal status (IGHF vs MPHD) and initial severity of GHD, as assessed by $\mathrm{GH}$ peak in a pharmacological test, had no effect on serum IGF-I SDS during GH treatment.

To date, only a few studies have assessed the value of serum IGF-I SDS monitoring for exploring the variability of serum IGF-I SDS during GH treatment in children with GH deficiency $(9,10,11,12,13,14,15,17)$. Previous studies have reported considerable individual biological variation of serum IGF-I SDS, as also found in this study, for all ages and treatment durations. There are several possible explanations for this variation of serum IGF-I SDS. Our findings are consistent with serum IGF-I SDS acting as a surrogate marker for individual adherence to treatment, as some patients with GHD had detectable serum IGF-I SDS values in the lower part of the reference range or even lower, potentially reflecting low levels of adherence to treatment. Contrary to previous reports of a significant decrease in adherence to treatment over time 
in children $(25,26,27,28,29)$ and adult (30) patients with GH deficiency, we observed no increase in the proportion of low serum IGF-I SDS values with age or treatment duration, and low serum IGF-I SDS values in our study were similarly distributed over different ages and treatment durations. However, it should be borne in mind that it is difficult to determine whether an individual low serum IGF-I SDS is due to poor adherence, low sensitivity to GH treatment or other factors, such as impaired nutritional status at the time of evaluation, and whether serum IGF-I values within the normal 2 SDS range reflect adequate administration for only a few days before the evaluation, as has been shown for patients with chronic disease, who improve their compliance behavior in the last few days before the appointment with their physician (31).

The higher serum IGF-I SDS values obtained for children with acquired GH deficiency than for those with non-acquired GH deficiency may result partly from insulin resistance. This finding is consistent with those of previous studies on long-term survivors of childhood cancer reporting a higher frequency of metabolic syndrome in this population, particularly after central nervous system tumors, acute lymphocytic leukemia, bone marrow transplantation, and related to hormonal deficiencies, drug or radiotherapy damage, endothelial impairment, physical inactivity and adipose dysfunction (32). We speculate that the higher IGF-I SDS values during GH therapy in patients with acquired GH deficiency may reflect differences in insulin levels and visceral adiposity. However, although most of these patients clearly had a BMI SDS in the upper part of the normal range, the biological significance of serum IGF-I SDS levels in these patients remains unclear, and the mechanisms underlying these higher levels remain to be elucidated.

One of the major strengths of this study is that it included a large number of patients, all diagnosed with GHD and belonging to a well-characterized population from a single pediatric clinical center. Furthermore, for each patient, serum IGF-I determinations carried out with the same assay, at a single laboratory, were included. However, this study also had several inherent limitations, due to the observational nature of retrospective data collection. Despite the inclusion of all children with GHD seen during the studied period, the median number of serum determinations per patient was small, and we were therefore unable to gain any further insight into the potential associations between growth and IGF-I SDS levels or changes in these associations (23). Oral estrogen replacement attenuates the serum IGF-I SDS response to $\mathrm{GH}$, whereas transdermal estrogen replacement does not $(33,34)$. Nevertheless, the effects of exogenous estrogen were not considered in our explanatory model, due to the small number of patients receiving oral estrogen $(n=8$ and $n=15$ of the patients with non-acquired and acquired GHD respectively), and this may have affected the findings. However, the comprehensive data collection in this study made it possible to estimate several important explanatory variables simultaneously and to use all observations in the estimation process.

In conclusion, this study provides important new insight into the relationship between serum IGF-I SDS and etiological group, which appears to be highly predictive of serum IGF-I SDS levels for all durations of GH treatment in children with GH deficiency. Further clinical studies are required to determine the precise mechanism by which etiological group affects serum IGF-I SDS, but these original findings have important clinical implications for long-term management and highlight the need for careful and appropriate monitoring of serum IGF-I SDS, particularly in patients with acquired GH deficiency, to prevent the unnecessary impact of potential comorbid conditions in these patients, although, to the best of our knowledge, target IGF-I SDS levels were not established so as to optimize the balance between potential risks and adult height gain.

Further studies are required to explore the associations between growth and IGF-I SDS levels, through regular, serial, longitudinal measurements of growth and serum IGF-I concentration. We hope that a combination of several parameters readily accessible in clinical practice will facilitate the follow-up and management of growth hormone treatment in patients with GH deficiency and improve the efficacy and safety of this therapy.

\section{Supplementary data \\ This is linked to the online version of the paper at http://dx.doi.org/10.1530/EJE-17-0215.}

Declaration of interest

D Mohamed, S Dos Santos, M Ben Azoun, D Chevenne and C Alberti have no conflicts of interest relevant to this manuscript to disclose. D Zénaty, $\mathrm{L}$ Martinerie and S Guilmin-Crepon have received support for travel to international meetings from several GH manufacturers. D Simon and A Paulsen are investigators in clinical trials using $\mathrm{GH}$ supplied by several manufacturers, and have received support for travel to international meetings from several GH manufacturers. J Léger and J C Carel are investigators in clinical trials using $\mathrm{GH}$ and in postmarketing studies with several brands of $\mathrm{GH}$, and have received support for travel to international meetings from several GH manufacturers. 


\section{Funding}

This study was supported in part by the French Ministry of Health (Rare Disease Plan). Data collection, analysis, interpretation, and the decision to submit the paper for publication were the responsibility of the authors alone.

\section{References}

1 Society GHR. Consensus Guidelines for the diagnosis and treatment of growth hormone deficiency in childhood and adolescence: summary statement of the Growth Hormone Reseach Society. Journal of Clinical Endocrinology and Metabolism 200085 3990_ 3993. doi:10.1210/jcem.85.11.6984

2 Wilson TA, Rose SR, Cohen P, Rogol AD, Backeljauw P, Brown $\mathrm{R}$, Hardin DS, Kemp SF, Lawson M, Radovick S et al. Update of guidelines for the use of growth hormone in children: the Lawson Wilkins Pediatric Endocrinology Society Drug and Therapeutics Committee. Journal of Pediatrics 2003143 415-421. (doi:10.1067/S0022-3476(03)00246-4)

3 Pollak MN, Schernhammer ES \& Hankinson SE. Insulin-like growth factors and neoplasia. Nature Reviews Cancer 20044 505-518. (doi:10.1038/nrc1387)

4 Grimberg A, DiVall SA, Polychronakos C, Allen DB, Cohen LE, Quintos JB, Rossi WC, Feudtner C \& Murad MH. Guidelines for growth hormone and insulin-like growth Factor-I treatment in children and adolescents: growth hormone deficiency, idiopathic short stature, and primary insulin-like growth factor-I deficiency. Hormone Research in Paediatrics 201686 361-397. (doi:10.1159/000452150)

5 Juul A, Dalgaard P, Blum WF, Bang P, Hall K, Michaelsen KF, Muller J \& Skakkebaek NE. Serum levels of insulin-like growth factor (IGF)-binding protein-3 (IGFBP-3) in healthy infants, children, and adolescents: the relation to IGF-I, IGF-II, IGFBP-1, IGFBP-2, age, sex, body mass index, and pubertal maturation. Journal of Clinical Endocrinology and Metabolism 199580 2534-2542.

6 Pokrajac A, Wark G, Ellis AR, Wear J, Wieringa GE \& Trainer PJ. Variation in GH and IGF-I assays limits the applicability of international consensus criteria to local practice. Clinical Endocrinology 20076765 70. (doi:10.1111/j.1365-2265.2007.02836.x)

7 Clemmons DR. Consensus statement on the standardization and evaluation of growth hormone and insulinlike growth factor assays. Clinical Chemistry 201157 555-559. (doi:10.1373/clinchem.2010.150631)

8 Alberti C, Chevenne D, Mercat I, Josserand E, Armoogum-Boizeau P, Tichet J \& Leger J. Serum concentrations of insulin-like growth factor (IGF)-1 and IGF binding protein-3 (IGFBP-3), IGF-1/IGFBP-3 ratio, and markers of bone turnover: reference values for French children and adolescents and z-score comparability with other references. Clinical Chemistry 201157 1424-1435. (doi:10.1373/clinchem.2011.169466)

9 Rikken B, van Doorn J, Ringeling A, Van den Brande JL, Massa G \& Wit JM. Plasma levels of insulin-like growth factor (IGF)-I, IGF-II and IGF-binding protein-3 in the evaluation of childhood growth hormone deficiency. Hormone Research $1998 \mathbf{5 0}$ 166-176. (doi:10.1159/000023268)

10 Tillmann V, Patel L, Gill MS, Whatmore AJ, Price DA, Kibirige MS, Wales JK \& Clayton PE. Monitoring serum insulin-like growth factor-I (IGF-I), IGF binding protein-3 (IGFBP-3), IGF-I/ IGFBP-3 molar ratio and leptin during growth hormone treatment for disordered growth. Clinical Endocrinology 200053 329-336. (doi:10.1046/j.1365-2265.2000.01105.x)

11 Cohen P, Bright GM, Rogol AD, Kappelgaard AM \& Rosenfeld RG. Effects of dose and gender on the growth and growth factor response to GH in GH-deficient children: implications for efficacy and safety. Journal of Clinical Endocrinology and Metabolism 200287 90-98. (doi:10.1210/jcem.87.1.8150)

12 Lanes R \& Jakubowicz S. Is insulin-like growth factor-1 monitoring useful in assessing the response to growth hormone of growth hormone-deficient children? Journal of Pediatrics 2002141 606-610. (doi:10.1067/mpd.2002.127662)

13 Ranke MB, Traunecker R, Martin DD, Schweizer R, Schwarze CP, Wollmann HA \& Binder G. IGF-I and IGF binding protein-3 levels during initial GH dosage step-up are indicators of GH sensitivity in GH-deficient children and short children born small for gestational age. Hormone Research 200564 68-76. (doi:10.1159/000087692)

14 Cutfield WS \& Lundgren F. Insulin-like growth factor I and growth responses during the first year of growth hormone treatment in KIGS patients with idiopathic growth hormone deficiency, acquired growth hormone deficiency, turner syndrome and born small for gestational age. Hormone Research 200971 (Supplement 1) 39-45. (doi:10.1159/000178036)

15 Siklar Z, Ocal G, Berberoglu M \& Bilir P. Combined evaluation of IGF-1 and IGFBP-3 as an index of efficacy and safety in growth hormone treated patients. Journal of Clinical Research in Pediatric Endocrinology 20091 240-243. (doi:10.4274/jcrpe.v1i5.240)

16 Ross JL, Lee PA, Gut R \& Germak J. Attaining genetic height potential: analysis of height outcomes from the ANSWER Program in children treated with growth hormone over 5 years. Growth Hormone and IGF Research 201525286 293. (doi:10.1016/j.ghir.2015.08.006)

17 Lundberg E, Kristrom B, Jonsson B \& Albertsson-Wikland K. Growth hormone (GH) dose-dependent IGF-I response relates to pubertal height gain. BMC Endocrine Disorders 201515 84. (doi:10.1186/s12902-015-0080-8)

18 Gelwane G, Garel C, Chevenne D, Armoogum P, Simon D, Czernichow P \& Leger J. Subnormal serum insulin-like growth factor-I levels in young adults with childhood-onset nonacquired growth hormone (GH) deficiency who recover normal GH secretion may indicate less severe but persistent pituitary failure. Journal of Clinical Endocrinology and Metabolism 200792 3788-3795. (doi:10.1210/jc.2007-1003)

19 Argyropoulou M, Perignon F, Brunelle F, Brauner R \& Rappaport R. Height of normal pituitary gland as a function of age evaluated by magnetic resonance imaging in children. Pediatric Radiology 199121 247-249. (doi:10.1007/BF02018614)

20 Sempé MPG \& Roy-Pernod MP. Auxologie, Méthodes et Séquences. Paris: Theraplix, 1970.

21 Rolland-Cachera MF, Cole TJ, Sempe M, Tichet J, Rossignol C \& Charraud A. Body Mass Index variations: centiles from birth to 87 years. European Journal of Clinical Nutrition 199145 13-21.

22 Hermanussen $\mathrm{M} \&$ Cole J. The calculation of target height reconsidered. Hormone Research 200359 180-183. (doi:10.1159/000069321)

23 Cohen P, Rogol AD, Howard CP, Bright GM, Kappelgaard AM \& Rosenfeld RG. Insulin growth factor-based dosing of growth hormone therapy in children: a randomized, controlled study. Journal of Clinical Endocrinology and Metabolism 200792 2480-2486. (doi:10.1210/jc.2007-0204)

24 Burman P, Johansson AG, Siegbahn A, Vessby B \& Karlsson FA. Growth hormone (GH)-deficient men are more responsive to GH replacement therapy than women. Journal of Clinical Endocrinology and Metabolism 199782 550-555.

25 Fisher BG \& Acerini CL. Understanding the growth hormone therapy adherence paradigm: a systematic review. Hormone Research in Paediatrics 201379 189-196. (doi:10.1159/000350251)

26 Kapoor RR, Burke SA, Sparrow SE, Hughes IA, Dunger DB, Ong KK \& Acerini CL. Monitoring of concordance in growth 
hormone therapy. Archives of Disease in Childhood 200893 147-148. (doi:10.1136/adc.2006.114249)

27 Rosenfeld RG \& Bakker B. Compliance and persistence in pediatric and adult patients receiving growth hormone therapy. Endocrine Practice 200814 143-154. (doi:10.4158/EP.14.2.143)

28 Haverkamp F, Johansson L, Dumas H, Langham S, Tauber M, Veimo D $\&$ Chiarelli F. Observations of nonadherence to recombinant human growth hormone therapy in clinical practice. Clinical Therapeutics 200830 307-316. (doi:10.1016/j.clinthera.2008.02.017)

29 Hartmann K, Ittner J, Muller-Rossberg E, Schonau E, Stephan R, Ullrich KP, Hoppe B, Ramseger R \& Bramswig J. Growth hormone treatment adherence in prepubertal and pubertal children with different growth disorders. Hormone Research in Paediatrics $2013 \mathbf{8 0}$ 1-5. (doi:10.1159/000351800)

30 Auer MK, Stieg MR, Hoffmann J \& Stalla GK. Is insulin-like growth factor-I a good marker for treatment adherence in growth hormone deficiency in adulthood? Clinical Endocrinology 201684 862-869. (doi:10.1111/cen.13030)
31 KyngAs HA, Kroll T \& Duffy ME. Compliance in adolescents with chronic diseases: a review. Journal of Adolescent Health 200026 379-388. (doi:10.1016/S1054-139X(99)00042-7)

32 Siviero-Miachon AA, Spinola-Castro AM \& Guerra-Junior G. Detection of metabolic syndrome features among childhood cancer survivors: a target to prevent disease. Vascular Health and Risk Management 20084 825-836. (doi:10.2147/VHRM.S2881)

33 Wolthers T, Hoffman DM, Nugent AG, Duncan MW, Umpleby M \& Ho KK. Oral estrogen antagonizes the metabolic actions of growth hormone in growth hormone-deficient women. American Journal of Physiology: Endocrinology and Metabolism 2001 281 E1191-E1196.

34 Isotton AL, Wender MC, Casagrande A, Rollin G \& Czepielewski MA. Effects of oral and transdermal estrogen on IGF1, IGFBP3, IGFBP1, serum lipids, and glucose in patients with hypopituitarism during GH treatment: a randomized study. European Journal of Endocrinology 2012166 207-213. (doi:10.1530/ EJE-11-0560)

Received 15 March 2017

Revised version received 14 June 2017

Accepted 29 June 2017 